Marketing in Asia Group

Asian Journal of Business Research

Volume 9 Issue 3, 2019

ISSN 2463-4522 e-ISSN 1778-8933

DOI: $10.14707 / a j b r .190066$

\title{
Encounter Experiences among Tourists at Attraction Sites - An Application of Social Contact Theory
}

\author{
Hsuan Hsuan Chang \\ Department of Leisure and Recreation Management, Ming Chuan University, Taiwan \\ Chin Chung Chiang \\ Institute of Business and Management, National Chiao Tung University, Taiwan
}

\begin{abstract}
This study uses the social contact theory to understand the attitudes of tourists towards other tourists, their encounter experiences, conflicts, and coping strategies used to overcome encounter conflict, and then investigates whether differences in these areas between American/Canadian and Chinese tourists are moderated by the recreational setting (indoor/outdoor). The study results show that Chinese tourists have more positive encounters with tourists who share their national background than with American/Canadian tourists, who for their own part experience more cultural conflict with other tourists in outdoor settings than do Chinese tourists. We conclude that the recreational setting moderates the relationship between American/Canadian and Chinese tourists, their level of encounter with other tourists, the type of conflict they experience, and the coping strategy used to ameliorate conflict. With respect to the latter, study participants at outdoors destinations, particularly American/Canadian tourists, prefer using an active adaptation strategy to overcome cultural and behavioural conflict, whereas those at indoor destinations prefer using an emotional strategy.
\end{abstract}

Keywords: Contact Theory, Tourist-to-Tourist Encounter, Encounter-Conflict, Adaptation Strategy

Publication Details: Received 12 Nov 2019; Revised 30 Nov 2019; Accepted 2 Dec 2019 


\section{Introduction}

According to MacCannell (1989), tourism can be viewed as a stage upon which human interactions take place. A study conducted by Dann and Phillips (2001) identifies three types of interaction at tourist sites: interaction between tourists and industry personnel, between tourists and hosts, and among tourists themselves. The quality of these different social interactions contributes significantly to a tourist's travel experience and to the success of the tourism destination. Previous studies have been directed primarily towards the interaction between tourists and hosts and the conflicts they may experience (Pizam, Uriely \& Reichel, 2000; Reisinger, 1994; Reisinger \& Turner, 2002a, 2002b) and between tourists and industry personnel (Dickson \& Huyton, 2008; Lee, Khan, \& Ko, 2008; McCleary, Weaver \& Hsu, 2007). However, few studies have attempted to provide an understanding of interactions among tourists themselves (Guthrie \& Anderson, 2007).

The importance of examining tourist-to-tourist interaction stems from the fact that tourism involves heterogeneity. Tourists are not a homogenous group of people; instead, they arrive from different countries and have different cultural backgrounds, preferences, traveling motives, and behaviours (Robinson \& Boniface, 1998). Yagi and Pearce (2007) suggest that tourists with different cultural backgrounds have different encounter preferences. Since people from different cultures have different norms regulating their range of acceptable behaviour in a given context, conflicts might arise among tourists visiting the same sites or traveling together (Manning et al., 2002; Vaske \& Donnelly, 2002). Reisinger (2009) explains encounter-conflict among tourists from the cultural difference perspective. According to social contact theory, the social interaction among people at these sites can reduce negative social phenomena under certain conditions.

Most studies in the outdoor recreational field have concluded that recreationists adopt unique strategies to overcome conflicts with others (Schneider \& Hammitt, 1995; Schuster et al., 2006). The quality of a tourist's on-site experience is an important factor in repeated tourism. A tourist's satisfaction is influenced by his or her interactions with other tourists at attraction sites, these interactions affect the quality of the on-site experience (Yagi \& Pearce, 2007). However, popular and promotional images of tourist destinations frequently omit the tourists themselves. What is more surprising is that there are limited studies of tourist-to-tourist interaction and few theories or guiding concepts in this area (Yagi \& Pearce, 2007).

In the past, social contact theory is always used to explain the interaction between residents and tourists (Joo et. al., 2018). The Contact Theory suggests that interaction under proper conditions can actually reduce negative social phenomena (Allport, 1954). However, the interaction should happen under proper conditions and then the interaction can reduce the negative experience. Therefore, many researches used Contact Theory to explain the reduction of negative sociocultural phenomena between residents and tourists of different culture background (Joo et al., 2018). The interactions will not just happen between residents and tourists. It also happens among tourists. Unfortunately, most studies have attempted to understand interactions between tourists and local people or between tourists and the environment but do not focus on interactions among tourists (Bochner, 1982; Guthrie \& Anderson, 2007; Wald et al., 2001). That explained the focus of this study is to examine encounter 
experiences among tourists of different national backgrounds (American/Canadian and Chinese) at different tourism sites (indoor/outdoor). The research goals are to understand these encounters and the conflicts that arise; to identify adaptation strategies used to ameliorate conflict; and to investigate whether differences in the level of interaction encountered (encounter level), the type of conflict experienced (behavioural versus cultural), and the adaptation strategy chosen, are moderated by the type of recreation site in which these encounters take place.

The paper is organized by reviewing relevant subjects including social contact theory, attitudes towards tourist-to-tourist encounters, encounter conflicts and coping strategies; then explaining the research methodology including the study participants, study instrument; presenting data analysis results for six research hypothesis. Then some research findings are discussed by comparing to previous studies and theoretical implications and future research topics are also provided afterwards. Two conclusions and two research limitations are mentioned in the end of this paper.

\section{Literature Review}

At tourism destinations, majority of contact with other tourists are cross-culture social interaction, which could be defined as the face-to-face contacts between people from different cultural backgrounds (Yu \& Lee, 2014). Fan, Zhang, Jenkins \& Tavitiyaman (2017) claimed that contact theory has been recognized as one of best approaches to elucidate intergroup relations. Wright, Aron, McLaughlinVolpe, and Ropp (1997) suggested that if the contact between group members can be properly managed, that could lead to better interaction results. That explained the reason that this study decided to use Social Contact Theory to investigate the relationship among attitudes of tourists towards other tourists, their encounter experiences, conflict and coping strategy.

\section{Social Contact/Interaction Theory}

In the sociology field, social contact theory emphasis the understanding cross-cultural social contact, also referred as cross-cultural social interaction. Some scholars also named social contact theory as social interaction theory which also discussed the issues such as cooperation, conflict, constraint, exchange and etc. (Sun, Cui, \& Xu, 2018). In social contact happening among different cultures is defined as the face-toface contacts between people from different cultural backgrounds (Cusher \& Brislin, 1996; Yu \& Lee, 2014). In tourist industry, the cross-cultural social contact has three relationship including between tourists and local residents, between tourists and industry personnel and among tourists. They might all appear in same attraction site because of different reasons. That meant tourists, local residents and industry personnel might have interaction conflicts because they play in different roles. So Nash (1989) argued that the relationship between tourists and their hosts need to develop certain mutual understand and acted upon it is to be maintained, which is similar to any other relationship. Tourists are not a homogenous group of people but rather arrive from different countries, and have varied cultures, preferences, traveling motives, and behaviors (Robinson \& Boniface, 1998). Consequently, tourists may experience culture shock from, and conflict with, other tourists (Nash, 1996). The role of culture in moderating social interactions, either positively or negatively, is widely 
accepted. According to Reisinger (2009), people belonging to a high-power-distance society (e.g., Japan) often need to know in advance the professional position of the person they are about to meet in order to determine the most appropriate way of interacting with that person. On the other hand, people from a low-power-distance society tend to think and act in the opposite way on this matter. Obviously, culture is a very by extension, one might conclude that tourists adapt different strategies to minimize uncomfortable feelings or conflict following an unpleasant encounter with other tourists. Some previous studies have examined the cultural differences between Japanese and Americans (Matsumoto et al., 1999; Matsumoto et al., 2002; Noguchi, 2007; Yrizarry et al., 1998). The differences between Americans and Japanese on how they manage passing encounters were found to be significant. According to Matsumoto (2006), Japanese who embrace a collectivistic culture tend not to show any expressive reactions to other people. Those previous studies all found that people with different culture background might have different perspectives regarding the social contact or interactions with others.

\section{Attitudes towards Tourist-to-Tourist Encounters}

Traveling abroad provides opportunities for individuals to interact with people of different cultural backgrounds. That makes tourists are surrounded by the social environment when traveling at a tourism destination (Fan et al., 2017). However, tourists may experience certain levels of culture shock and majority of them will not adapt to those unpleasant situations because they may just stay at that destination for a short period of time. Most studies have attempted to understand interactions between tourists and local people or between tourists and the environment; they do not focus on interactions among tourists (Bochner, 1982; Guthrie \& Anderson, 2007; Wald, et al., 2001). Yagi (2001) collects 830 articles from 120 Japanese and American online travel gurus and uses content analysis to understand direct and indirect encounters among tourists and their attitudes towards both other tourists and local industry personnel. Overall, Yagi (2001) shows that the attitudes of the Japanese and Americans differ significantly from each other.

Several previous studies have examined the cultural differences between the Japanese and Americans (Matsumoto et al., 1999; Matsumoto et al., 2002; Noguchi, 2007; Yrizarry et al., 1998). Significant differences have been found between how Americans and the Japanese manage passing encounters. According to Matsumoto (2006), the Japanese, who belong to a collectivistic culture, tend not to show expressive reactions to other people. In a study of pedestrian interactions in Japan and the United States, Patterson et al. (2007) found that although Japanese pedestrians glance at others only slightly less frequently than do American pedestrians, there are much larger differences between the groups with respect to smiles, nods and greetings. They also showed that the 'look and smile' condition receives greater responses than the 'look-only' condition, which supports the findings of another study indicating that participants smile in response to another person's smile (Hindsz \& Halberstadt, 1991). 
Yagi and Pearce (2007) find different encounter preferences between Japanese and American/Canadian study participants with respect to both appearance and the number of people encountered. The Japanese prefer mixing with American/Canadian people, at least in the rainforest setting studied, whereas Americans/Canadians do not have marked appearance-related preferences. With respect to the preferred number of people in the setting, Americans/Canadians are inclined to favour few or no other people, whereas the Japanese prefer some people and are tolerant of larger numbers. The current research, which focuses on the differences between American/Canadian and Chinese tourists because Chinese tourists ranked Top one of inbound tourists with Eastern culture and American/Canadian tourists ranked Top one of inbound tourists with Western culture, considers the possible influence of recreational setting on the above study findings, and extrapolates from this inference to propose the following hypothesis:

H1 American/Canadian and Chinese tourists have different preferences (attitudes) towards encounter experiences with tourists of different nationalities at different recreational settings.

\section{Encounter-conflicts}

Although social contact theory suggested cross culture interaction could be an effective way to reduce prejudice between group members under certain conditions, such as equal status, common goals, intergroup cooperation, support of authorities as well as personal interaction (Allport, 1954). Similar idea was also proposed by Nash (1989), which is the relationship between tourists and their hosts requires certain understandings that must be agreed and acted upon if it is to be maintained. The same idea could be also applying to the situation among tourists. Both Nash (1996) and Robinson (1998) have identified the possibility of cultural conflicts between groups of tourists and conclude that stereotypical views of a nationality can affect on-site interaction. Conversely, Urry (1990) and De Botton (2002) argue that it is the presence of other visitors that 'makes' tourist sites; this means that the very presence of other tourists can enhance site appreciation and worthiness. The subject of encounter-conflict has been considered in the outdoor recreational field for almost four decades, where it is used to explain the interaction among recreationists (Fishbein \& Ajzen, 1975; Manning, 1999; Parasuraman, Zeithaml \& Berry, 1985). In outdoor recreation, the crowded caused by too many recreationists at the same destination might lead to injuries, conflicts, and dissatisfaction (Usher \& Gomez, 2017). This might also happen at tourist sites. Cultural differences can also affect the outcomes of cross-cultural interactions in the service industry (Sizoo et al., 2005). These differences may create perceptions of mistrust and an "us versus them" mentality (Hunter, 2001). It is suggested that similar cultural backgrounds are conducive to attractive service interactions (Hartel \& Fujimaoto, 2000; Yoo \& Sohn, 2003), whereas different cultural backgrounds promote interactions marked by feelings of strangeness, anxiety, fear and conflict, often with negative consequences (Neuliep \& Ryan, 1998). 
Cross-cultural interactions among tourists can lead to misunderstandings or encounter-conflicts. Some researchers have focused on interpersonal conflict (Jacob \& Schreyer, 1980; Schneider, 2000), whereas others have examined social value conflict (Carothers, Vaske \& Donnelly, 2001). Interpersonal conflict occurs when the presence or behaviour of an individual or group interferes with the goals of another individual or group (Jacob \& Schreyer, 1980). This interference or conflict might manifest as direct competition over resources or as physical incompatibilities between groups (Bury, Holland \& McEwen, 1983). Interpersonal conflict normally occurs between different activity groups and in outdoor recreational settings rather than indoor recreation sites.

Another type of conflict is named as "social value conflict" and typically occurs between people or groups of people who have dissimilar norms/values related to an activity (Vaske et al., 1995). Social value conflict normally occurs when there is no direct contact between the parties involved (Carothers et al., 2001). For example, when someone's unintentional behaviour violates the expectations of another person, a violation that occurs because the two people have different communicative norms, that violation might be perceived either favourably or unfavourably. If the encounter experience is in accordance with someone's expectations or norms, the perception is almost universally considered as a positive encounter experience.

In the outdoor recreational field, eco-tourists typically do not accept behaviours such as defloration or littering in national parks (Carothers, Vaske \& Donnelly, 2001; Manning, 1999; Tynon \& Gomez, 2012). Also, rafters have been shown to dislike seeing motorboats at nature areas even though there is no direct encounter between them and the people driving the motorboats (Thapa \& Graefe, 1999). Anderson and Brown (1984) find that visitors sometimes have to change their habits by selecting different entry points or different sites, because other people display behaviour deemed inappropriate; this includes behaviour related to usage level, litter, noise, and environmental impact. These are all forms of social value conflict, not interpersonal conflict. The following hypothesis addresses these different types of conflict with respect to recreational setting:

H2 Tourists experience different types of encounter-conflict in different recreational settings.

When people travel abroad and visit an unfamiliar destination they cannot expect to avoid interactions/encounters with tourists of different nationalities. However, even when traveling within one's home country, tourists might expect to encounter people from differing countries at popular destination sites, due to the prevalence of international travel. Studies have shown that people with different cultural backgrounds may have different social norms, values, and definitions of appropriate or acceptable behaviour (Brislin, Cushner, Cherrie \& Yong, 1986). In the context of tourism, the presence of other tourists or behaviour that is unfamiliar, such as making noise in a museum or littering in a natural park, might cause unpleasant feelings even if these intrusions do not interfere with a tourist's goals (Jackson \& Wong, 1982; Rudell \& Gramann, 1994). 
Pizam and Fleischer (2005) have discovered that subjects with different cultural backgrounds prefer different types of tourist activities. Subjects from individualist cultures (e.g., the U.S.A.) prefer more dynamic and active tourist activities than those coming from collectivist cultures (e.g., Japan). With different expectations and preferences, tourists might experience aspects of culture shock and conflict related to other tourists (Nash, 1996), who do not share their attitudes, beliefs, values, and preferred activities (Robinson, 1998). Unfortunately, most studies investigate this cultural conflict in the context of the tourist-host relationship (Brown, 1999; Pearce, 1993). The following hypothesis addresses this conflict as it pertains to the tourist-totourist relationship:

H3 Tourists with different nationality or cultural backgrounds experience different types of encounter-conflict.

\section{Encounter-conflict Coping Strategies}

According to the social contact theory, the intergroup contact or interaction could cause positive changes in attitude towards the members of the 'other' group when the contact occurs under favourable conditions. The favourable condition could be perceived equality in status, common goals, intergroup cooperation, and support for contact (Pettigrew, 1998). In another word, the contact or interaction could cause negative change in attitude and create some conflicts if the conditions are unfavourable. So, at recreation research filed, encounter conflicts occur at both outdoor and indoor recreation sites because recreationists might share same space but engage in different recreation activities. With regard to outdoor sites, previous research has found that visitor satisfaction may remain relatively high even when a park's use levels increase (Manning, 1999). Manning and Valliere (2001) formulate a possible explanation that involves strategies for coping in response to crowding or conflict at destination sites. For example, recreationists may choose to visit certain destinations less often or to stop going to popular destinations altogether. Coping is a psychological concept and different recreationists have different ways of coping with encounter-conflicts. In general, however, coping is defined as any behaviour that reduces stress and enables a person to manage a situation without excessive stress (Sutherland, 1996). It can also be defined as a process used by an individual to manage a problem in his or her environment (Schneider \& Wynveen, 2015). Manning (1999) identifies three primary coping mechanisms: displacement, rationalization and product shift. With respect to cross-cultural conflict, Amani (2012) categorizes eight types of conflict resolution: competition, neglect, emotional expression, third-party help, compromise, avoidance, obligation/accommodation, and collaboration and integration. This classification is not incompatible with the analysis of Manning, and some overlap might be found between different categories; avoidance, for example, might be seen as a form of displacement and compromise a type of rationalization.

Displacement is considered a primary behavioural coping mechanism that involves spatial or temporal changes in use patterns in response to conflict. As usage levels of certain destinations increase, visitors sometimes abandon them, thus altering their patterns of recreational activity (Tynon \& Gómez, 2012; Schneider \& Wynveen, 2015). Previous studies have found that changes in recreational activity manifest themselves in different ways. These include limits to the number of attraction sites visited, limits to the time spent at each tourism site, and alterations in the frequency of 
visits to a tourism site, which may affect the days the site is in operation. Any one of these changes can result in an ultimate or temporal displacement of conflict. However, displacement is not always a suitable coping strategy, especially when tourists travel overseas. The majority of overseas tourists plan their itinerary in advance and cannot easily change it. In these situations, rationalization and product shift are cognitive coping mechanisms that may alter tourists' perceptions of their recreational experiences and opportunities. Many people who rationalize an experience report high levels of satisfaction, regardless of the conflict. With these observations in mind, the following hypothesis is proposed:

H4 To overcome encounter-conflicts, international tourists prefer rationalization coping strategies to displacement or product shift coping strategies.

Tourists often have different perceptions of what constitutes an acceptable encounter in crowded situations (Manning et al., 2002). Kyle et al. (2004) and Manning (1999) note that individual differences in encounter-conflicts and encounter norms are affected by different factors. One of those factors pertains to the individual characteristics of tourists, including their travel purposes, previous traveling experience, cultural identity and nationality. Manning (2003) has found significant differences in the encounter norms of multicultural tourists to North America. Similarly, Nash (1996) and Robinson (1998) have found that tourists with different national backgrounds sometimes encounter conflict at tourist destinations due to their cultural differences. Evidently, any social interaction is invariably influenced by a variety of factors pertaining to the social rules adopted by the participants (Argyle, Henderson \& Furnham, 1985). These rules are culturally determined and while the interaction among tourists might be framed by what is referred to as an encompassing "tourist culture," it is equally determined by their respective national cultures (Pizam, 1999). Concerning the eight types of cross-cultural conflict resolution proposed by Amani (2012), Lather, Jain and Shukla (2011) have found that competition is more favoured by cultures influenced by American identity, whereas members of Asian countries show an opposite pattern to Americans. In India, the most preferred style of resolving conflict is accommodation followed by avoidance. Koreans prefer using compromise and avoidance, as do the Chinese and Japanese, whereas Malaysians prefer comprise and integration. With respect to the coping strategies adopted to overcome these encounter-conflicts, the following hypothesis is proposed:

H5 American/Canadian and Chinese tourists prefer different coping strategies to overcome encounter-conflicts at different recreational settings.

Numerous studies have suggested that as usage levels of particular destination sites increase, some recreationists become dissatisfied and alter their patterns of recreational activity to avoid crowding (Hammitt \& Patterson, 1991; Robertson \& Regula, 1994). In this manner, they are "displaced" by recreationists that are more tolerant of higher usage levels. Displacement does not have to involve a shift from one recreation area to another. It can also involve shifts within a recreation area or shifts from one usage period to another, also known as temporal displacement. There are more opportunities for tourists to shift from one area to another at outdoor recreation sites than at indoor sites, where shifting to other areas might pose challenges. In these sites, temporal displacement might be the preferred coping strategy. For example, the Chiang Kai-Shek memorial hall is an open-space 
destination that is crowded only at certain times. Tourists still can visit CKS during unpopular time periods. However, the National Palace Museum, a top tourist destination, is always full of people eager to see the spectacular exhibitions and displays. The NPM is always crowded and there are lengthy waits; therefore, displacement, including temporal displacement, is not a suitable coping strategy in this environment.

Another possible coping strategy, mentioned previously, is rationalization. Because recreational activities are voluntarily selected and sometimes involve a substantial investment of time, money, and effort, some people may choose to rationalize their experience and report a high level of satisfaction regardless of the actual conditions they encounter. Rationalization has been shown to be a common coping strategy in outdoor settings (Heberlein \& Shelby, 1977; Hoss \& Brunson, 2000), where interpersonal conflict, as it has been noted, also tends to be higher. Based on these observations, the following hypothesis is proposed:

H6 Differences in interactions, encounter-conflicts and adaptation strategies between American/Canadian and Chinese tourists are moderated by the type of recreational setting (indoor/outdoor).

\section{Methodology}

\section{Study Participants}

This is a cross-sectional study that used a closed-end questionnaire to collect data at two recreational settings, indoor and outdoor. The two data-collection sites were the National Palace Museum (NPM, indoor) and National Dr. Sun Yat-Sen Memorial Hall (NDSYSMH, outdoor). The research team collected 611 questionnaires from the two sites (312 indoors and 299 outdoors) from September 2016 to March 2017. According to chi-square analysis, the study participants at the two sites were of significantly different ages, and had significantly different national backgrounds and educational backgrounds. According to the 2016 Survey Report on Visitors Expenditure and Trends in Taiwan conducted by the Taiwan Tourism Bureau, inbound tourists are categorized by their place of origin including continent and nationality. Among the Asian market, Chinese tourism ranks first. Among the nonAsian market, Americans and Canadians rank first. Therefore, the study collected data only from Chinese tourists and American/Canadian tourists.

Female study participants (55.8\%) outnumbered male participants (44.2\%). Approximately $46.1 \%$ of the participants were between 21 and 30 years old, and another $23.5 \%$ were under 21 years old. On average, study participants at NPM were older than the participants at NDSYSMH. Unsurprisingly, this study surveyed more Chinese tourists $(64.9 \%)$ than American/Canadian tourists $(35.1 \%)$, reflecting the preponderance of Asians among Taiwan's inbound tourism market. Approximately $64 \%$ of both groups had a college-level educational background (Table 1). Overall, study participants had abundant foreign travel experience. Ninety percent reported travel abroad at least one to three times per year. With this level of overseas travel experience, they had many opportunities to interact with other tourists at tourism attraction sites. Moreover, most of the study participants $(67 \%)$ reported a preference 
for independent travel as opposed to group tours, increasing their opportunities to encounter local people, but also other tourists. Forty-two percent of the respondents indicated that they have foreign relatives and regular interactions with foreigners in their daily lives.

Table 1: The Socioeconomic Backgrounds of the Study Participants

\begin{tabular}{|c|c|c|c|c|c|c|c|c|c|}
\hline & \multirow{2}{*}{\multicolumn{2}{|c|}{ Variable }} & \multicolumn{2}{|c|}{ Indoor } & \multicolumn{2}{|c|}{ Outdoor } & \multicolumn{2}{|c|}{ Total } & \multirow{2}{*}{$\chi^{2}$} \\
\hline & & & \# & $\%$ & \# & $\%$ & \# & $\%$ & \\
\hline \multirow{3}{*}{$\begin{array}{l}\mathscr{Q} \\
\stackrel{9}{9} \\
\stackrel{9}{4}\end{array}$} & Male & & 141 & 45.5 & 128 & 43.0 & 269 & 44.2 & \multirow{3}{*}{0.39} \\
\hline & Female & & 169 & 54.5 & 170 & 57.0 & 339 & 55.8 & \\
\hline & Total & & 310 & 100.0 & 298 & 100.0 & 608 & 100.0 & \\
\hline \multirow{6}{*}{ 学 } & Under 20 & & 41 & 13.2 & 101 & 34.4 & 142 & 23.5 & \multirow{6}{*}{$47.62 * * *$} \\
\hline & 21 30 & & 163 & 52.4 & 116 & 39.5 & 279 & 46.1 & \\
\hline & $31 \sim 40$ & & 76 & 24.4 & 37 & 12.6 & 113 & 18.7 & \\
\hline & 41 50 & & 17 & 5.5 & 24 & 8.2 & 41 & 6.8 & \\
\hline & Over 51 & & 14 & 4.5 & 16 & 5.4 & 30 & 5.0 & \\
\hline & Total & & 311 & 100.0 & 294 & 100.0 & 605 & 100.0 & \\
\hline \multirow{3}{*}{ 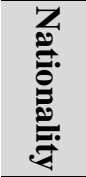 } & American/Ca & adian & 132 & 42.7 & 81 & 27.3 & 213 & 35.1 & \multirow{3}{*}{$32.28 * * *$} \\
\hline & Chinese & & 177 & 57.3 & 216 & 72.7 & 393 & 64.9 & \\
\hline & Total & & 309 & 100.0 & 297 & 100.0 & 606 & 100.0 & \\
\hline \multirow{5}{*}{ 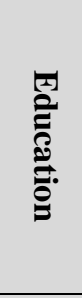 } & Junior high & & 3 & 1.0 & 4 & 1.4 & 7 & 1.2 & \multirow{5}{*}{$21.71 * * *$} \\
\hline & Senior high & & 25 & 8.1 & 60 & 20.7 & 85 & 14.2 & \\
\hline & College & & 207 & 66.8 & 177 & 61.0 & 384 & 64.0 & \\
\hline & Graduate & & 75 & 24.2 & 49 & 16.9 & 124 & 20.7 & \\
\hline & Total & & 310 & 100.0 & 290 & 100.0 & 600 & 100.0 & \\
\hline \multirow{4}{*}{ 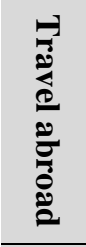 } & $\mathbf{0}$ & 14 & 4.6 & 52 & & 7.7 & 66 & 11.1 & \multirow{4}{*}{$56.64 * * *$} \\
\hline & $1 \sim 3$ & 201 & 66.3 & 214 & & 3.0 & 415 & 69.6 & \\
\hline & 4 10 & 87 & 29.1 & 27 & & 9.2 & 115 & 19.3 & \\
\hline & Total & 303 & 100.0 & 293 & & 0.0 & 596 & 100.0 & \\
\hline \multirow{3}{*}{ 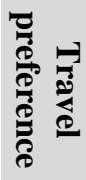 } & Group & 99 & 31.9 & 101 & & 5.2 & 200 & 33.5 & \multirow{3}{*}{0.71} \\
\hline & Self & 211 & 68.1 & 186 & & 4.8 & 397 & 66.5 & \\
\hline & Total & 310 & 100.0 & 287 & & 0.0 & 597 & 100.0 & \\
\hline \multirow{3}{*}{ 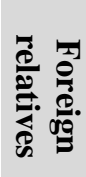 } & $\overline{\text { No }}$ & 181 & 59.5 & 165 & & 5.7 & 346 & 57.7 & \multirow{3}{*}{0.89} \\
\hline & Yes & 123 & 40.5 & 131 & & 4.3 & 254 & 42.3 & \\
\hline & Total & 304 & 100.0 & 296 & & 0.0 & 600 & 100.0 & \\
\hline
\end{tabular}




\section{Study Instrument}

This study's questionnaire was based on previous work developed to evaluate the encounter conflict and coping strategy in outdoor recreation field. So, a few modifications (such as recreationist changed to tourists) were required in view of the special characteristics of the tourism destination (Taiwan). The questions were translated into traditional Chinese and English. A four-page questionnaire was designed that included the participants' frequency of encounter with other tourists, encounter experiences, conflicts, preferred adaptation strategy in encounter-conflicts, socio-economic information (e.g. gender, educational background, occupation and income level), and traveling habits.

\section{Encounter Experience}

Study participants reported on the frequency of their encounters with three types of tourists at the different attraction sites. The first type were tourists of the same nationality as the study participants; the second type were tourists of a different nationality, but categorized as Chinese based on their appearance; and the third type were tourists of a different nationality categorized as American/Canadian based on their appearance. The encounter frequency was measured on a 7-point scale defined as "how often the participants had encounters/interactions with other tourists at attraction sites." The scale ranged from Not at all (1) to Always (7). The larger the number, the more often the participants had encounters with other tourists. Study participants were also asked about their attitudes towards the three types of tourists following certain encounters/interactions.

\section{Encounter-conflicts}

The encounter-conflicts experienced by the study participants support the research that people from different cultures may not have the same attitudes, beliefs, values and expectations in different encounter settings (Robinson, 1998). The majority of instruments used to measure conflict have been designed for use in outdoor recreation sites (Manning, 1999; Carothers et al., 2001, \& Schuster et al., 2006). This study proposed ten questions on a 7-point Likert scale to evaluate the participants' responses to different encounter-conflict situations with other tourists. One question was designed as follows: "I had conflicts with other tourists because they looked strangely at my clothes." Other items along the same line of questioning included "my skills, language, and living habits." Another question was designed as follows: "Other tourists shouted loudly or engaged in improper behaviour (e.g., littering, spitting, and smoking)." The scale ranged from Not at all (1) to Very much (7). The larger the number, the more serious the study participant considered the encounter-conflict.

\section{Adaptation/Coping Strategy}

In this study, adaptation or coping strategy is conceptually defined as the reaction used by a study participant to minimize the negative influence of encounter-conflict with other tourists. According to previous studies (Schneider, Hammitt \& Moore, 2003; Lazarus \& Folkman, 1984), there are two types of adaptation strategies: emotional and behavioural. This study measured the emotional coping strategy of tourists with five items presented as statements, two of which were the following: "I 
endure uncomfortable encounters with other tourists" and "I tell myself to enjoy the experience if I cannot make the situation better". The behavioural coping strategy of the study participants was also measured by five items presented as statements, one of which was the following: "I change my travel plans to avoid an uncomfortable situation." The ten coping strategies were measured using Guttmann-type scales, which required that they be ranked in some order so that the response pattern of a study participant could be captured by a single index. This means that an individual who agreed with a particular item also agreed with items of lower rank-order. According to the pilot study result, the CR value for the Guttmann coping strategy instrument with ten items was 0.887 . This indicates a highly reliable measurement.

\section{Results}

\section{Encounters/Interactions with Other Tourists}

This research studied the frequency of the study participants' encounters with other tourists at the same attraction sites and the quality of those encounters. Encounter frequency was defined as how often tourists experienced encounters/interactions with other tourists at attraction sites. The scale ranged from Not at all (1) to Always (7). The larger the number, the more often the participants had encounters with other tourists. According to the $\mathrm{T}$ test, there is a significant difference between American/Canadian and Chinese tourists at indoor and outdoor sites. Obviously, American/Canadian tourists had more encounters with other tourists of a different cultural background than did Chinese tourists. Overall, tourists had a higher chance of encountering other tourists at indoor sites than at outdoor sites.

Table 2: Frequency of Encounter Experiences with Other Tourists at Attraction Sites

\begin{tabular}{lcccccccccc} 
& \multicolumn{3}{c}{ Total sample } & \multicolumn{3}{c}{ Indoor } & \multicolumn{3}{c}{ Outdoor } \\
\cline { 2 - 10 } Encounter & $\mathbf{A} / \mathbf{C}$ & $\mathbf{C}$ & $\mathbf{T}$ & $\mathbf{A} / \mathbf{C}$ & $\mathbf{C}$ & $\mathbf{T}$ & $\mathbf{A} / \mathbf{C}$ & $\mathbf{C}$ & $\mathbf{T}$ \\
\hline \multirow{2}{*}{4.77} & 3.54 & $7.44 * * *$ & 4.94 & 3.69 & $6.38 * * *$ & 4.34 & 3.42 & $3.11 * *$ \\
\hline$* 0.001, * * \mathrm{p}<0.01, * \mathrm{p}<0.05$ & & & & & & &
\end{tabular}

The study hypothesis \# 1 also analysed the participants' attitudes towards encounters with three different types of tourists: (1) tourists of the same nationality; (2) Chinese tourists; and (3) American/Canadian tourists. The participants' attitudes were categorized as positive, neutral or negative. In all samples, the percentages of responses indicating a neutral attitude towards the three types of tourists were very similar at approximately $60 \%$. The percentage of responses indicating a positive attitude towards other tourists of the same nationality was the highest at $36 \%$, whereas the percentage indicating a positive attitude towards Chinese tourists was the lowest at $28 \%$. Furthermore, the study used six cross tabs to examine the association between tourists with different national backgrounds and attitudes towards three different types of tourists at different attraction sites. In Table 3, three of the six cross tab analyses showed a significant association. 
For the samples at the indoor attraction site, two of three cross tab analyses showed significant results. Tourists with different national backgrounds had significantly different attitudes towards encounters with other tourists who were either of the same nationality or American/Canadian. At outdoor attractions, one of three cross-tab analyses showed a significant result. Tourists with different national backgrounds had significantly different attitudes towards encounters with tourists of the same nationality. Chinese tourists had a more positive attitude towards other tourists of the same nationality than towards American/Canadian tourists. The same result was also found at indoor attraction sites. At both attraction sites, approximately $70 \%$ of tourists had a neutral attitude towards encounters with other tourists. The cross-tab analysis of attitudes towards encounters with American/Canadian tourists showed very different results between the indoor and outdoor samples. For samples at indoor sites, Chinese tourists showed more negative attitudes towards American/Canadian tourists, and also fewer positive attitudes towards American/Canadian tourists than the latter showed towards each other. However, whether positive, negative or neutral, attitudes were very similar between Chinese and American/Canadian tourists at outdoor attraction sites.

Table 3: Cross-Tab Analysis of Encounter Attitudes by Tourists with Different National Backgrounds at Two Attraction Sites

\begin{tabular}{l|r|r|r|r|r}
\hline \multicolumn{1}{c|}{\begin{tabular}{c} 
Three Types of \\
\multicolumn{1}{c|}{ Tourists }
\end{tabular}} & \multicolumn{2}{|c|}{ Attitudes towards Encounter } & \multicolumn{2}{c}{ Cross-tab Analysis Result } \\
\cline { 2 - 6 } & Negative & Neutral & Positive & \multicolumn{1}{c}{ Indoor } & \multicolumn{1}{c}{ Outdoor } \\
\hline Same nationality & $3 \%$ & $61 \%$ & $36 \%$ & $\mathbf{6 . 8 4 3}^{*}$ & $\mathbf{9 . 7 0 1}$ \\
Chinese tourists & $7 \%$ & $64 \%$ & $28 \%$ & 2.967 & 1.316 \\
$\begin{array}{l}\text { American/Canadian } \\
\text { tourists }\end{array}$ & $7 \%$ & $58 \%$ & $34 \%$ & $\mathbf{8 . 2 3 1}^{*}$ & 5.559 \\
\hline
\end{tabular}

**p $<0.01,{ }^{*} \mathrm{p}<0.05$

\section{Encounter-Conflict with the Level of Encounter and with Other Tourists}

The study participants rated 10 items, shown in Table 4, to express the extent to which they encountered conflict with other tourists. The participants' responses to the 10 items were combined and subjected to a principal component analysis with two factor solutions specified. The KMO value was 0.873(>0.6), the Bartlett's Chi-Square value was 3489.65 , and the $\mathrm{p}$ value was less than .05 . Two domains were identified for factor analysis: the cultural aspect of encounter-conflict and the behavioural aspect of encounter conflict. All of the factors had eigenvalues greater than one and explained $68.25 \%$ of the total variance. Moreover, the correlation between the two factors was 0.10 , showing that they were relatively independent. Factor I was named the "cultural aspect of encounter-conflict." This first factor consisted of six types of encounter-conflict with other tourists caused by cultural differences between the two parties. The cultural differences pertained to clothing, skin colour, language, living habits, etc. Factor II was named the "behavioural aspect of encounter conflict" and consisted of four types of encounter-conflict caused by actual behaviours. These were behaviours that might result in an uncomfortable noise/smell or involve impolite or rude behaviours to others (Table 4). 
Table 4: The Factor Analysis of Encounter-Conflict at Attraction Sites

\begin{tabular}{|c|c|c|}
\hline I had conflict with other tourists "BECAUSE" & $\begin{array}{l}\text { Cultural } \\
\text { Aspect }\end{array}$ & $\begin{array}{l}\text { Behavioral } \\
\text { Aspect }\end{array}$ \\
\hline Other tourists looked strangely at my clothes. & .870 & \\
\hline Other tourists looked strangely at my skin color. & .885 & \\
\hline Other tourists reacted strangely to my language. & .823 & \\
\hline Other tourists looked strangely at my living habits. & .867 & \\
\hline Other tourists touched me accidently. & .605 & \\
\hline I sensed that other tourists disliked me. & .726 & \\
\hline I heard other tourists shouting loudly. & & .778 \\
\hline Other tourists tried to sell me things. & & .733 \\
\hline I saw other tourists damage scenic spots. & & .868 \\
\hline $\begin{array}{l}\text { I saw other tourists engage in improper behavior such as } \\
\text { littering, spitting, smoking, bargaining, etc. }\end{array}$ & & .844 \\
\hline Reliability $(\alpha)$ & 0.90 & 0.85 \\
\hline Eigenvalue & 4.86 & 1.97 \\
\hline Percentage of explained variance & 40.23 & 28.02 \\
\hline
\end{tabular}

The study also examined study participants' level of encounter with other tourists on a 7-point scale. The scale ranged from Not at all (1) to Always (7). The larger the number, the more often the participants encountered other tourists. The average score for the level of encounter was approximately 4 out of 7 . Next, two regression models were used to examine the extent to which the level of encounter affected the encounter experience. The F-value pertaining to cultural conflicts during an encounter was 9.071, which decreased to 1.261 in the model examining behavioural conflict. This means that the more encounters study participants had with other tourists, the higher the possibility was that they experienced cultural conflicts with these tourists.

Next, the study used the T-test to examine differences in cultural and behavioural aspects of conflict between American/Canadian and Chinese tourists at the two types of attraction sites (Table 5). American/Canadian and Chinese tourists both experienced more behavioural conflict than cultural conflict at the two attraction sites (study hypothesis \#2). This means that tourists were most sensitive to behaviours they considered inappropriate, such as loud talking, smoking, touching or pushing in line, etc. Normally, the definition of good or proper behaviour is determined by the standards shared by members of a social group or country, whereas personal norms are unique to individuals and reflect an individual's own expectations. In a crosscultural situation, different people might have different expectations about what constitutes proper behaviour at indoor and outdoor attraction sites. 
Regarding cultural conflicts, no significant difference was exhibited between American/Canadian and Chinese tourists at indoor attraction sites; however, a significant difference was found between tourists of different cultural backgrounds at outdoor attraction sites. At these sites, American/Canadian tourists experienced more cultural conflict than did Chinese tourists. This explained the result of third study hypothesis.

Table 5: Conflict among Tourists of Different National Backgrounds at Different Attraction Sites

\begin{tabular}{lccccccccc}
\hline & \multicolumn{3}{c}{ Total sample } & \multicolumn{3}{c}{ Indoors } & \multicolumn{3}{c}{ Outdoor } \\
\cline { 2 - 11 } Cultural & $\mathbf{A} / \mathbf{C}$ & $\mathbf{C}$ & $\mathbf{T}$ & $\mathbf{A} / \mathbf{C}$ & $\mathbf{C}$ & $\mathbf{T}$ & $\mathbf{A} / \mathbf{C}$ & $\mathbf{C}$ & $\mathbf{T}$ \\
\cline { 2 - 11 } & $\mathbf{2 . 1 6}$ & $\mathbf{0 . 4 3}$ & 1.86 & 2.32 & -1.78 & 3.25 & 2.02 & $3.56^{* * *}$ \\
\hline Behavioral & 4.04 & 4.20 & -0.76 & 3.90 & 4.04 & -0.50 & 4.40 & 4.33 & 0.18 \\
\hline T value & $-10.35^{*}$ & $-16.40^{*}$ & & $-16.65^{*}$ & $-20.81^{*}$ & & $-18.75^{*}$ & $-18.9 *$ & \\
\hline$* * \mathrm{p}<0.001, * * \mathrm{p}<0.01, * \mathrm{p}<0.05$ & & & & & &
\end{tabular}

\section{Adaption/Coping Strategy for Encounter-Conflicts}

Coping strategy was measured using the Guttmann scale with ten statements with which study participants could express their agreement or disagreement by using a "check or not check" mark. Again, ten coping-strategy items were arranged in a particular order according to the result of pilot tests, so that an individual who agreed with a particular item also agreed with lower-ranked items. The lower the rank order, the higher was the opportunity to use a soft or emotional coping strategy. The higher the rank order, the higher was the opportunity to use a more active or behavioural coping strategy.

According to the cross-tab result, cultural background does not have a significant impact on coping strategy preferences when a tourist encounters conflict with other tourists (study hypothesis \#5). However, different attraction sites do elicit different coping strategies among all tourists $(\chi 2=119.13$, $\mathrm{P}$ value $<0.000)$. If participants encounter conflict with other tourists at an indoor attraction site, they convince themselves to continue enjoying the tour even if they cannot control or ameliorate the conflict. This is one type of rationalization strategy. If the conflict occurs at an outdoor attraction site, the coping strategy is similar but not identical in all instances. While tourists tend to simply accept the unpleasant situation and convince themselves to embrace it with a pleasant attitude, a small percentage of people (17\%) choose to consider the uncomfortable situation as an opportunity to enhance their self-image. These tourists are willing to accept and show respect to others in outdoor recreation sites. Overall, this study showed that international tourists prefer to use rationalization coping strategies to overcome conflict, not displacement or product-shift coping strategies (study hypothesis \#4). 
Table 6: Conflict Coping Strategy at Different Attraction Sites

\begin{tabular}{lrrrr} 
& \multicolumn{2}{c}{ Indoors } & \multicolumn{2}{c}{ Outdoors } \\
\cline { 2 - 5 } & Guttmann Scale & \% & $\#$ & \multicolumn{1}{c}{$\boldsymbol{\%}$} \\
\hline I silently endure an uncomfortable situation. & 47 & 15.1 & 34 & 11.4 \\
\hline $\begin{array}{l}\text { I tell myself that it is not unusual to encounter } \\
\text { uncomfortable situations. }\end{array}$ & 26 & 8.4 & 14 & 4.7 \\
\hline $\begin{array}{l}\text { I tell myself to enjoy the experience if I cannot make } \\
\text { the situation better. }\end{array}$ & $\mathbf{8 2}$ & $\mathbf{2 6 . 4}$ & 55 & 18.4 \\
\hline $\begin{array}{l}\text { I tell myself that the uncomfortable situation isn't } \\
\text { really that bad. }\end{array}$ & 25 & 8.0 & 27 & 9.0 \\
\hline $\begin{array}{l}\text { I consider an uncomfortable situation as an } \\
\text { opportunity to enhance my self-image. }\end{array}$ & 52 & 16.7 & $\mathbf{5 7}$ & $\mathbf{1 9 . 1}$ \\
\hline $\begin{array}{l}\text { I change my travel plans to avoid uncomfortable } \\
\text { situations. }\end{array}$ & 27 & 8.7 & 15 & 5.0 \\
\hline $\begin{array}{l}\text { I reduce the number of my visits to avoid } \\
\text { uncomfortable situations. }\end{array}$ & 15 & 4.8 & 24 & 8.0 \\
\hline $\begin{array}{l}\text { I express my feelings or anger to whoever causes an } \\
\text { uncomfortable situation. }\end{array}$ & 11 & 3.5 & 19 & 6.4 \\
\hline \begin{tabular}{l} 
I complain to the manager. \\
\hline I tell myself never visit the site again.
\end{tabular} & 17 & 5.5 & 41 & 13.7 \\
\hline Total & 9 & 2.9 & 13 & 4.3 \\
\hline *The chi-square value is 119.13. & $\mathbf{1 0 0 . 0}$ & $\mathbf{2 9 9}$ & $\mathbf{1 0 0 . 0}$ \\
\hline
\end{tabular}

\section{The Moderating Effect of Recreational Setting}

Two-way ANOVA was used to examine study hypothesis \#6. The dependent variables were the level of encounter with other tourists, cultural conflict, behavioral conflict, and adaptation strategy. The independent variable was the nationality of the study participants (Chinese or American/Canadian). The moderating variables were the types of recreational setting (indoor/outdoor). As shown in Table 7, the two-way ANOVA test reveals significant interaction between recreational setting and a tourist's national background with respect to the level of encounter with other tourists $(\mathrm{F}$ value $=5.569, \mathrm{p}=0.019)$ and the perception of cultural conflict $(\mathrm{F}$ value $=10.060$, $\mathrm{p}=0.002$ ). Figure 1 shows that the recreational setting moderates the relationship between a tourist's national background and his or her level of encounter with other tourists. While, among Chinese participants, no significant difference was observed between levels of encounter with other tourists at indoor and outdoor recreation sites, among American/Canadian participants significant differences were found. American/Canadian study participants had a higher level of encounter with other tourists when they spent time at an indoor recreation site as opposed to outdoor recreation site.

Figure 2 shows that the recreational setting also moderates the relationship between a tourist's national background and his or her level of cultural conflict. Chinese study participants' experienced higher levels of cultural conflict at indoor recreation sites than at outdoor recreation sites. However, American/Canadian study participants 
experienced higher levels of cultural conflict at outdoor recreation sites than at indoor recreation sites. A two-way ANOVA test reveals no significant interaction between study participants of different national backgrounds with respect to perceptions of behavioural conflict and adaptation strategy. Because of this test result, a one-way ANOVA test was used for testing the interaction of national background and recreational setting on perceptions of behavioural conflict and choice of adaptation strategy. The result is illustrated in Tables 5 and 6.

Table 7: Two-Way ANOVA Test on Level of Encounter, Encounter-Conflict, and Adaptation Strategy as Moderated by Recreational Setting and National Background

\begin{tabular}{l|l|r|r|r|r}
\hline Recreation & \multicolumn{1}{c|}{$\begin{array}{c}\text { Nationality } \\
\text { Sites }\end{array}$} & background & $\begin{array}{c}\text { Level of } \\
\text { Encounter }\end{array}$ & \multicolumn{1}{c|}{$\begin{array}{c}\text { Encounter Conflict } \\
\text { Culture }\end{array}$} & \multicolumn{1}{c}{ Bdaptation } \\
Indovior & Strategy \\
\hline \multirow{2}{*}{ Indoors } & Chinese & 10.39 & 13.8912 & 16.1419 & 4.28 \\
& American/Canadian & 13.62 & 11.5963 & 16.2857 & 4.09 \\
\hline \multirow{2}{*}{ Outdoors } & Chinese & 9.99 & 12.1307 & 17.3314 & 5.07 \\
& American/Canadian & 11.64 & 15.9661 & 18.5556 & 5.17 \\
\hline Recreation & F value & 12.409 & 1.823 & 6.311 & 19.487 \\
Site & Sig. & 0.000 & 0.178 & 0.012 & 0.000 \\
\hline Nationality & F value & 52.726 & 0.635 & 0.987 & 0.053 \\
Background & Sig. & 0.000 & 0.426 & 0.321 & 0.818 \\
Interaction & F value & 5.569 & 10.060 & 0.615 & 0.489 \\
Effect & Sig. & $\mathbf{0 . 0 1 9}$ & $\mathbf{0 . 0 0 2}$ & 0.433 & 0.485 \\
\hline
\end{tabular}

Figure 1: Interaction Plot on Level of Encounter

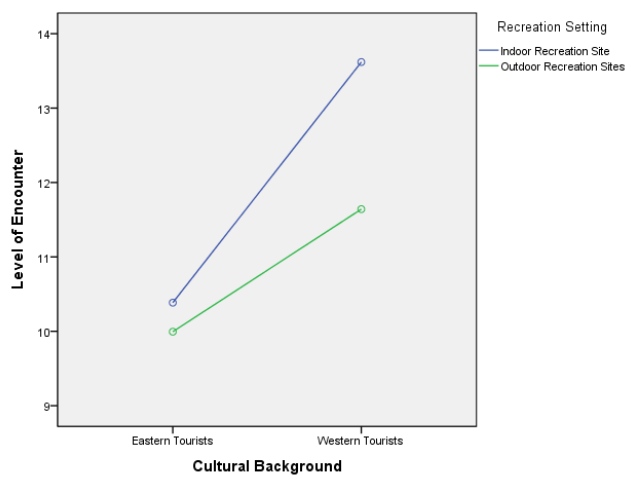

Figure 2: Interaction Plot on Level of Cultural Aspect Conflict

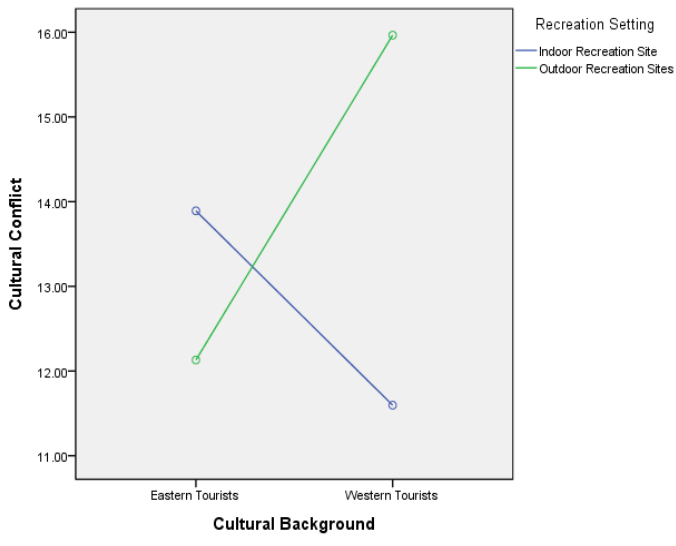




\section{Evaluation of Coping/Adaptation Strategies Used By Study Participants with Different National Backgrounds}

Coping strategies were investigated using a regression approach. Two regression models were presented because of the results of the two-way ANOVA test, which showed a moderating effect of national background on adaptation strategy. The dependent variable was the type of coping/adaptation strategy used. The higher the rank order, the higher was the opportunity to use a more active or behavioural coping strategy. The independent variables were the level of encounter, experience of cultural conflict, behavioural conflict and recreational setting (measured as a dummy variable). The result, listed in Table 8 , shows that only recreational setting significantly affected the coping strategy of the Chinese participants. If study participants encountered conflict at outdoor recreation sites, the possibility of using a more active coping strategy was higher. Among the American/Canadian study participants, three independent variables, but not level of encounter, had a significant effect on the choice of coping strategy. Based on these results, the study concludes that the choice of coping strategy is not determined by the level of encounter, either directly or indirectly, but by other variables.

Table 8: Regression Result on Coping Strategy

\begin{tabular}{lrrrrrr}
\hline & \multicolumn{3}{c}{ Chinese $^{* 1}$} & \multicolumn{4}{c}{ American/Canadian $^{* 2}$} \\
\cline { 2 - 7 } & $\boldsymbol{\beta}$ & $\boldsymbol{t}$ & Sig. & $\boldsymbol{\beta}$ & $\boldsymbol{t}$ & Sig. \\
\hline (Constant) & 4.133 & 8.390 & .000 & 2.129 & 3.563 & .000 \\
Encounter & -.034 & -.968 & .334 & .036 & .956 & .340 \\
Cultural Conflict & .020 & 1.467 & .143 & .038 & 2.699 & $\mathbf{. 0 0 7}$ \\
Behavioral Conflict & .015 & .801 & .424 & .064 & 3.136 & $\mathbf{. 0 0 2}$ \\
Recreational Setting & .838 & 2.899 & $\mathbf{. 0 0 4}$ & .817 & 2.579 & $\mathbf{0 1 0}$ \\
\hline
\end{tabular}

*1 The R-square is 0.042 and model's F-value is 3.45 .

*2 The R-square is 0.131 and model's F-value is 10.19 .

\section{DISCUSSION}

The increasing number of inbound tourists in Taiwan causes crowding at tourism sites and conflict among tourists. The number and diversity of these tourists to Taiwan's tourist sites has raised concern about the potential effects on the quality of travel experiences in Taiwan. To address this concern, this study focused on two tourist sites in Taiwan: The National Palace Museum (NPM), the major tourist destination of Taipei, which receives more than ten million tourists a year and typically involves high levels of expenditure, time and effort for tourists to arrange; and the National Dr. Sun Yat-Sen Memorial Hall (NDSYSMH), an outdoor tourist destination.

The study explored the tourist-to-tourist encounter phenomenon. This area of inquiry has received little attention in the past, despite the fact that an understanding of these interactions has possible implications for practical management. The overall aim of the study was to examine how tourists view other tourists, the types of conflict they experience, and the coping strategies they use to avoid dissatisfaction. The study had a further aim of analysing the moderating effect of national background and recreational setting on the encounter experience of tourists. This section discusses the 
study's major findings, the academic value of these findings, and their practical implications.

\section{Encounter/Interaction with Other Tourists}

The study found that both Chinese and American/Canadian tourists prefer to encounter tourists of their own nationality at outdoor attraction sites, and that Chinese tourists express a negative reaction towards American/Canadian tourists at indoor sites. This result could be explained by the stereotypical ideas associated with tourists. For example, previous studies have shown that Japanese tourists tend to isolate themselves, rather than mingle with other nationalities. Others studies have reported that many of their survey participants made negative comments towards either Japanese or American tourists. However, most studies have shown that encounters with other tourists are perceived as neutral to mildly pleasant experiences that are especially appreciated because of the opportunity to receive travel information. An exception to this overall positivity was Japanese respondents' relatively negative opinions of their own image as tourists.

The interaction between individuals of different national backgrounds can also be analysed from a service encounter perspective (Bitner, 1990). Tourism as a service involves the interaction of tourists from various national backgrounds and with local residents. This intermingling can lead to service encounter failures and dissatisfaction with overseas travel. Thyne and Lawson (2001) suggested that failed encounter experiences might be explained by social distance theory. Social distance is an expression of sympathetic understanding and management of individual differences (Chapman, Gajewska-De Mattos, Clegg, \& Buckley, 2008). In this study, the results of the two-way ANOVA show that American/Canadian tourists had a higher level of encounter with other tourists at indoor recreation sites than at outdoor sites. For Chinese tourists, the level of encounter with other tourists was quite low and similar for both attraction sites.

\section{Encounter-Conflict with Other Tourists}

This study also found that the higher the level of encounter, the more cultural conflict (as opposed to behavioural conflict) tourists experienced. Both American/Canadian and Chinese tourists experienced more behavioural conflict than cultural conflict at the two attraction sites. Yagi's (2001) study confirms that tourists who have more time to be exposed to other tourists, including those from different countries, find their encounters more enjoyable, and that encountering a large number of other tourists with whom they have little contact, either direct or indirect, is perceived as negative. In other words, crowding is an issue in the tourism industry. In Taiwan, it is very normal to see crowds of tourists from different countries at the same popular tourist destination. Crowding is often considered intrinsically negative, linked to the violation of a social norm.

This study found that at outdoor attraction sites, American/Canadian tourists experienced more cultural conflict than did Chinese tourists. This finding is very similar to the result for outdoor recreation areas in previous research. In outdoor recreation areas, conflict occurs between different activity groups, such as nonmotorized and motorized watercraft or skiers and snowboarders. These recreationists 
share a leisure environment for their different activities, which can lead to interpersonal or social value conflict (Schneider \& Budruk, 1999). Crowding is a less serious issue in the context of outdoor recreation, which might explain why there is less behavioural conflict than cultural conflict at outdoor sites. In this study, the Chinese study participants experienced a higher level of cultural conflict at indoor recreation sites than at outdoor sites, whereas American/Canadian tourists experienced a higher level of cultural conflict at outdoor recreation sites than at indoor sites.

\section{Coping Strategy towards the Encounter-Conflict}

This study found that at higher levels of encounter-conflict, study participants (especially American/Canadian) were more likely to use active or behavioural coping methods. This supports the finding of Miller \& Mccool (2003), who argue that respondents with lower levels of stress are more likely to engage in certain cognitive adjustments to cope with unpleasant situations. Respondents reporting higher levels of stress are more likely to engage in either direct action aimed at changing environmental conditions or displacement from the recreational setting.

The study also found that international tourists prefer to use rationalization strategies to overcome their encounter-conflicts, rather than displacement or product-shift strategies. They simply accept an unpleasant situation and convince themselves to embrace the situation with a pleasant attitude. This result reinforces the findings of previous research. Heberlein and Shelby's (1977) study finds that a Colorado River boater who has selected a specific trip and invested time and money into that recreational experience might weigh these issues against any perceived dissatisfaction and rationalize a satisfactory experience. Other coping strategies such as spatial displacement or product shift are common in outdoor recreational activities; those strategies include changing destinations or substituting another type of outdoor recreational activity. These strategies might be explained by the high cost in time and money of traveling aboard and the fixed nature of the travel itinerary, which is arranged with other tourists. Under these circumstances, tourists might not be able to use spatial movement to cope with the encounter-conflict. Previous studies have documented that the product shift coping strategy is rarely used due to the inherent difficulty of measuring such a cognitive change. Rationalization is used when recreationists have invested highly in their self-selected outdoor recreational activity (Heberlein \& Shelby, 1977; Hoss \& Brunson, 2000). Since traveling abroad involves a high expenditure of time and money and the travel itinerary is fixed and arranged with other tourists, those who travel abroad might not be able to use spatial movement to counteract encounter-conflict. Adopting other strategies to decrease the negative feelings caused by encounter-conflict may be more effective.

Another explanation of the coping strategy chosen is the degree to which the conflict causes stress. Research has shown that higher stress levels are more strongly related to absolute displacement behaviour, whereas lower stress levels provide an occasion for cognitive adjustment (Miller \& Mccool, 2003). Moderate stress levels are more closely associated with substitution behaviours. For the purposes of this study, these findings suggest that the study participants may have encountered more conflict than reported; however, the conflict was tolerated rather than seen as serious cause for action. 


\section{Theoretical Implications}

This study examines crowding, conflicts, and coping strategies of inbound tourists at two different types of attraction sites. Most studies have traditionally viewed recreation conflict according to behaviour, which is also same as at tourism attraction sites. Majority of tourists encountered conflicts due to the behaviour aspects rather than cultural aspects. Using the Social Contact theory, tourist with Western cultural background (American/Canadian) are more willing to have more contact with other tourists with high social difference but still cannot avoid the out-group encounter conflict. Later on, using the coping strategy developed by Manning (1999), this study continued to explore the encounter conflict with the different group (out-group) tourists. But, Yagi's (2001) study found opposite result that tourists who have more time to be exposed to other tourists, including those from different countries, find their encounters more enjoyable. In this study, study participants only had a very limited encounter with other tourists due to time constraint or other reasons but did not have real and deep contact and interactions with other tourists. So the short time encounter could easily end up negative experience. Moreover, there are still many other variables that should be explored for out-group conflict and in-group conflict among tourists with the same nationality is also another subject which has not been researched. It is important to examine out-group conflict among tourists with different nationality background, who have to share the same destination during certain period of time (because their travel itinerary is always fixed and arranged by travel agency), and this issue requires more attention especially at indoors attraction sites due to the crowding problems.

\section{CONCLUSION}

This research investigated tourist-to-tourist encounters at different recreation sites, the conflicts that occur at these sites, and the extent to which the culture or national background of the participants affects the encounter experience. The findings show that both the encounter level of tourists (i.e., frequency of encounter) and the type of conflict they experience (behavioural or cultural) is moderated by national background and recreational setting (indoor/outdoor). In addition, when traveling abroad, tourists tend to use rationalization as a coping strategy to ameliorate conflict. These findings will benefit the literature on encounter-conflict and coping strategies in international tourism studies.

At outdoor recreation sites, some previous studies proposed the usage of zoning strategy as a resolution to this conflict (Kainzinger, Burns \& Arneberger, 2015; Tynon \& Gómez, 2012). The zoning strategy could be a method to solve out-group conflict at outdoor attraction sites (Usher \& Gomez, 2017). But zoning could not be a suitable strategy to solve the conflict happening in out-group conflicts at tourism attraction sites because majority of inbound tourists have very tight schedule for each destination and their traveling itinerary might be decided by travel agency or planned in advanced. Besides it is very unlikely for inbound tourists to choose visiting the overcrowding destination at different times (temporal displacement strategy). Because of those reasons, it is very obvious that inbound tourists deal with the conflicts by using emotional strategy at indoors sites. For the destination management organization, they can probably apply the concept of carrying capacity at popular 
tourist attraction sites in order to manage tourist density and crowding issue, especially at indoor attraction sites. The popular indoors destination can even consider the usage of appointment system and all the tourists to apply for the visitation in advance, especially for the tour visitation.

Secondly, destination planners should not only communicate to tourists the need to behave properly, but also need to put the code of conduct at the entrance of attraction sites. For example, policies regulating smoking, dress, and other tourist behaviours may go a considerable distance to ameliorate or eliminate dissatisfaction (Martin \& Pranter, 1989). The staff working at tourism sites should be trained to provide a "warm up" act to get the tourist ready and in the right frame of mind as a tourist (Grove \& Fisk, 1992). Providers should educate customers as to the behaviour expected of them and the kinds of behaviour not allowed when visiting their service landscapes (Bowen, 1986; Bowers, Martin \& Luker, 1990). Moreover, all of the tour guides and tour leaders might also be educated to provide the information regarding the proper behavior at attraction sites and also the code of conduct. In sum, if marketing and operations managers combine their energies in an effort to implement these tactics to leverage tourist compatibility, encounters with other tourists may increase a tourist's travel satisfaction, rather than decrease it through conflict.

Overall, tourist-to-tourist encounters appear to be an important part of the travel experience for many tourists insofar as they influence travel-satisfaction levels. In time, the development of research on this type of encounter in the tourist industry might benefit the management of tourist businesses and sites as they grapple with issues of tourist crowding and the need to meet the expectations of multinational markets. In particular, providing opportunities for tourist interaction as well as tourist independence might prove a valuable strategy for managing conflict. Another management strategy that may reduce the worst effects of tourist-to-tourist conflict includes establishing better queue management to overcome the perception of crowding at destination sites and to promote better access to resources. In addition, more site-specific analyses of tourists' reactions to other tourists of their own and other nationalities might provide a basis for management decisions regarding mixing and separating tourist markets.

There are two limitations to interpreting and generalizing this study's findings. First, because of its research budget, the study collected data only in Taipei, not in Taiwan as a whole. Although Taipei is the destination site of the majority of Chinese tourists to Taiwan, future research might consider collecting data from other well-known tourist attractions such as Sun Moon Lake or Kenting National Park. Those destinations are popular and always crowded. The second research limitation is the use of random sampling for data collection. Random sampling was chosen because of the survey's languages: English and Chinese. Tourists who did not understand English or Chinese were excluded from this study even though they may have expressed a desire to participate. These study limitations do not negate the cumulative effort of the research undertaken, but instead represent an acknowledgement of the directions in which this work could be improved. 


\section{Implications for Asian Business Context}

This research investigated tourist-to-tourist encounters at different recreation sites, the conflicts that occur at these sites, and the extent to which the culture or national background of the participants affects the encounter experience. In Asia, majority of attraction sites are full of tourists. The study results provide some implications for travel and tourism business operators. First of all, the concept of carrying capacity can be applied at popular tourist attraction sites to manage tourist density and crowding issue, especially at indoor attraction sites. The popular indoors destination can even consider the usage of appointment system and all the tourists to apply for the visitation in advance, especially for the tour visitation. Secondly, destination planners of travel and tourism industry should communicate to tourists the need to behave properly, but also need to put the code of conduct at the entrance of attraction sites. And then travel and tourism managers should also train the staffs working at tourism sites to provide a "warm up" act to get the tourist ready and in the right frame of mind as a tourist. Thirdly, all of the tour guides and tour leaders might also be educated to provide the information regarding the proper behaviour at attraction sites and also the code of conduct to tourists. In sum, if marketing and operations managers combine their energies in an effort to implement the carrying capacity concepts at attraction site and also these tactics to leverage tourist compatibility, encounters with other tourists may increase a tourist's travel satisfaction, rather than decrease it through conflict.

\section{References}

Allport, G. W., (1954), The nature of prejudice, Addison-Wesley Publishing, Cambridge.

Anderson, G., \& Brown, R. I. F., (1984), "Real and laboratory gambling, sensation - seeking and arousal", British Journal of Psychology, vol. 75, no. 3, pp. 401-410.

Argyle, M., Henderson, M., \& Furnham, A., (1985), "The rules of social relationships", British Journal of Social Psychology, vol. 24, no. 2, pp. 125-139.

Avruch, K., (1998), "Culture \& conflict resolution", International Journal on World Peace, vol. 16 , no. 2 , pp. 81-83.

Bitner, M. J., (1990), "Evaluating service encounters: The effects of physical surroundings and employee responses", Journal of Marketing, vol. 54, no. 2, pp. 69-82.

Bochner, S., (1982), Cultures in contact: Studies in cross-cultural interaction, Elsevier Publishing, Pergamon.

Botton, A. D., (2002), The art of travel, Hamish Hamilton, London.

Bowen, D. E., (1986), "Managing customers as human resources in service organizations", Human Resource Management, vol. 25, no. 3, pp. 371-383.

Bowers, M. R., Martin, C. L., \& Luker, A., (1990), "Trading places: Employees as customers, customers as employees", Journal of Services Marketing, vol. 4, no. 2, pp. 55-69.

Brislin, R. W., Cushner, K., Cherrie, C., \& Yong, M., (1986), International interactions: A practical guide - Cross-cultural research and methodology issues, Sage Publications, London.

Brown, T. J., (1999), "Antecedents of culturally significant tourist behaviour", Annals of Tourism Research, vol. 26, no. 3, pp. 676-700.

Bury, R. L., Holland, S. M., \& McEwen, D. N., (1983), "Analysing recreational conflict: Understanding why conflict occurs is requisite to managing that conflict", Journal of Soil and Water Conservation, vol. 38, no. 5, pp. 401-403.

Carothers, P., Vaske, J. J., \& Donnelly, M. P., (2001), "Social values versus interpersonal conflict among hikers and mountain bikers", Leisure Sciences, vol. 23, no. 1, pp. 47-61. 
Chapman, M., Gajewska-De Mattos, H., Clegg, J., \& Buckley, P. J., (2008), "Close neighbours and distant friends: Perceptions of cultural distance", International Business Review, vol. 17, no. 3, pp. 217-234.

Dann, G., Phillips, J., Faulkner, B., Moscardo, G., \& Laws, E., (2001), Qualitative tourism research in the late twentieth century and beyond, In Faulkner, B., Moscardo, G., \& Laws, E., Tourism in the twenty-first century: Reflections on experience, Continuum Publishing, London.

Fan, D. X. F., \& Zhang, H. Q., Jenkins, C. L., \& Tavitiyaman, P., (2017), “Tourist typology in social contact: An addition to existing theories", Tourism Management, vol. 60, pp. 357-366.

Fishbein, M., \& Ajzen, I., (1975), Belief, attitudes, intention, and behaviour: An introduction to theory and research, Addison-Wesley, Massachusetts.

Grove, S. J., \& Fisk, R. P., (1992), "Observational data collection methods for services marketing: An overview", Journal of the Academy of Marketing Science, vol. 20, no. 3, pp. 217-224.

Guthrie, C., \& Anderson, A., (2007), Tourists on tourists: The impact of other people on destination experience, In Tribe, J., \& Airey, D., Developments in tourism research, Elsevier Ltd, Oxford.

Hartel, C., \& Fujimaoto, Y., (2000), "Diversity is not a problem to be managed by organizations but openness to perceived dissimilarity is", Journal of Australian and New Zealand Academy of Management, vol. 6, no. 1, pp. 14-27.

Hammitt, W. E., \& Patterson, M. E., (1991), "Coping behaviour to avoid visitor encounters: Its relationship to wildland privacy", Journal of Leisure Research, vol. 23, no. 3, pp. 225-237.

Heberlein, T. A., \& Shelby, B., (1977), "Carry capacity, values, and the satisfaction model: A reply to Greist", Journal of Leisure Research, vol. 9, no. 2, pp. 142-148.

Hindsz, V. B., \& Tomhave, J. A., (1991), "Smile and (half) the world smiles with you, frown and you frown alone", Personality and Social Psychology Bulletin, vol. 17, pp. 586592.

Hoss, A. F., \& Brunson, M. W., (2000), Meanings and implications of acceptability judgements for wilderness use impacts, In Cole, D. N., McCool, S. F., Borrie, W. T., O'Loughlin, J., Wilderness science in a time of change, United States Department of Agriculture, Forest Service, Rocky Mountain Research Station, Ogden.

Hunter, W. C., (2001), "Trust between culture: The tourist", Current Issues in Tourism, vol. 4, no. 1, pp. 42-67.

Jackson, E. L., \& Wong, R. A. G., (1982), "Perceived conflict between urban cross-country skiers and snowmobilers in Alberta", Journal of Leisure Research, vol. 14, no. 1, pp. 47-63.

Jacob, G. R., \& Schreyer, R., (1980), "Conflict in outdoor recreation: A theoretical perspective", Journal of Leisure Research, vol. 12, no. 4, pp. 368-380.

Joo, D., Tasci, D. A., Woosnam, K. M., Maruyama, N. U., Hollas, C. R., \& Aleshinloye, K. D., (2018), "Residents' attitude towards domestic tourists explained by contact, emotional solidarity and social distance", Tourism Management, vol. 64, pp. 245-257.

Kainzinger, S., Burns, R. C., \& Arneberger, A., (2015), "Whitewater boater and angler conflict, crowding and satisfaction on the North Umpqua river, Oregon", Human Dimensions of Wildlife: An International Journal, vol. 20, no. 6, pp. 542-552.

Kyle, U. G., Bosaeus, I., De Lorenzo, A. D., Deurenberg, P., Elia, M., Gómez, J. M., \& Scharfetter, H., (2004), "Bioelectrical impedance analysis - part I: Review of principles and methods", Clinical Nutrition, vol. 23, no. 5, pp. 1226-1243.

Lazarus, R. S., \& Folkman, S., (1984), Stress, appraisal, and coping, Springer Publishing Company, New York.

Lee, K., Khan, M. A., \& Ko, J. Y., (2008), "A cross-national comparison of consumer perceptions of service recovery", Journal of Travel \& Tourism Marketing, vol. 24, no. 1, pp. 1-16. 
MacCannell, D., (1989), "Introduction to special issue on the semiotics of tourism", Annals of Tourism Research, vol. 16, no. 1, pp. 1-6.

Manning, R., (1999), Studies in outdoor recreation: Search and research for satisfaction, Oregon State University Press, Corvallis.

Manning, R., (2003), "What to do about crowding and solitude in parks and wilderness? A reply to Stewart and Cole", Journal of Leisure Research, vol. 35, no. 1, pp. 107-118.

Manning, R. E. \& Valliere, W. A., (2001), "Coping in outdoor recreation: Causes and consequences of crowding and conflict among community residents", Journal of Leisure Research, vol. 33, no. 4, pp. 410-426.

Manning, R., Lawson, S., Newman, P., Laven, D., \& Valliere, W., (2002), "Methodological issues in measuring crowding-related norms in outdoor recreation", Leisure Sciences, vol. 24, pp. 339-348.

Martin, C. L., \& Pranter, C. A., (1989), "Compatibility management: Customer-to-customer relationships in service environments", Journal of Services Marketing, vol. 3, no. 3, pp. $5-15$.

Matsumoto, D., (1999), "Culture and self: An empirical assessment of Markus and Kitayama's theory of independent and interdependent self-construal", Asian Journal of Social Psychology, vol. 2, no. 3, pp. 289-310.

Matsumoto, D., (2006), "Culture and nonverbal behaviour", Handbook of Nonverbal Communication, pp. 219-235.

Matsumoto, D., Consolacion, T., Yamada, H., Suzuki, R., Franklin, B., Paul, S., \& Uchida, H., (2002), "American-Japanese cultural differences in judgements of emotional expressions of different intensities", Cognition \& Emotion, vol. 16, no. 6, pp. 721-747.

McCleary, K. W., Weaver, P. A., \& Hsu, C. H., (2007), "The relationship between international leisure travellers' origin country and product satisfaction, value, service quality, and intent to return", Journal of Travel \& Tourism Marketing, vol. 21, no. 2-3, pp. 117-130.

Miller, T. A., \& Mccool, S. F., (2003), "Coping with stress in outdoor recreational settings: An application of transactional stress theory", Leisure Sciences, vol. 25, pp. 257-275.

Mohsin, A., (2006), "Cross-cultural sensitivities in hospitality: A matter of conflict or understanding", In International Conference on Excellence in the Home: Balanced dietbalanced Life.

Nash, D., (1989), Tourism as a form of imperialism, In Smith, V. L., Hosts and guests: The anthropology of tourism, University of Pennsylvania Press, Philadelphia.

Nash, T. H., (1996), Lichen biology, Cambridge University Press, Cambridge.

Neuliep, J. W., \& Ryan, D. J., (1998), "The influence of intercultural communication apprehension and socio-communicative orientation on uncertainty reduction during initial cross-cultural interaction", Communication Quarterly, vol. 46, no. 1, pp. 88-99.

Noguchi, T., (2007), "Light-induced FTIR difference spectroscopy as a powerful tool toward understanding the molecular mechanism of photosynthetic oxygen evolution", Photosynthesis Research, vol. 91, no. 1, pp. 59-69.

$\mathrm{Ou}, \mathrm{C} .$, \& Wu, J., (2007), "Persistence of wave-fronts in delayed nonlocal reaction-diffusion equations", Journal of Differential Equations, vol. 235, no. 1, pp. 219-261.

Parasuraman, A., Zeithaml, V. A., \& Berry, L. L., (1985), "A conceptual model of service quality and its implications for future research", Journal of Marketing, vol. 49, no. 4, pp. 41-50.

Patterson, K., Nestor, P. J., \& Rogers, T. T., (2007), "Where do you know what you know? The representation of semantic knowledge in the human brain", Nature Reviews Neuroscience, vol. 8, no. 12, pp. 976-987.

Pearce, P. L., (1993), Fundamentals of tourist motivation, In Pearce, D. G., \& Butler, R. W., Tourism research: Critiques and challenges, Routledge, London.

Pettigrew, T. F., (1998), "Intergroup contact theory", Annual Review of Psychology, vol. 49, no. 1 , pp. 65-85.

Pizam, A., (1999), "A comprehensive approach to classifying acts of crime and violence at tourism destinations", Journal of Travel Research, vol. 38, no. 1, pp. 5-12. 
Pizam, A., \& Fleischer, A., (2005), "The relationship between cultural characteristics and preference for active vs. passive tourist activities", Journal of Hospitality \& Leisure Marketing, vol. 12, no. 4, pp. 5-25.

Pizam, A., Uriely, N., \& Reichel, A., (2000), "The intensity of tourist-host social relationship and its effects on satisfaction and change of attitudes: The case of working tourists in Israel", Tourism Management, vol. 21, no. 4, pp. 395-406.

Reisinger, Y., (1994), "Tourist - Host contact as a part of cultural tourism", World Leisure \& Recreation, vol. 36, no. 2, pp. 24-28.

Reisinger, Y., \& Turner, L. W., (2002), "Cultural differences between Asian tourist markets and Australian hosts" (Part 1 \& Part 2), Journal of Travel Research, vol. 40, no. 3, pp. 295-315. DOI: $10.1177 / 0047287502040003008$

Robertson, R. A., \& Regula, J. A., (1994), "Recreational displacement and overall satisfaction: A study of Central Iowa's licensed boaters", Journal of Leisure Research, vol. 26, no. 2, pp. 174-181.

Robinson, B. E., (1998), "The workaholic family: A clinical perspective", American Journal of Family Therapy, vol. 26, no. 1, pp. 65-75.

Robinson, M., \& Boniface, P., (1998), Tourism and cultural conflicts, CABI Publishing, New York.

Ruddell, E. J., \& Gramann, J. H., (1994), "Goal orientation, norms, and noise - Induced conflict among recreation area users", Leisure Sciences, vol. 16, no. 2, pp. 93-104.

Schneider, I. E., \& Budruk, M., (1999), "Displacement as a response to the federal recreation fee program", Journal of Park \& Recreation Administration, vol. 17, no. 3, pp. 76-84.

Schneider, I. E., \& Wynveen, C., (2015), "Exploring outdoor recreation conflict's role in evolving constraints models", Journal of Outdoor Recreation and Tourism, vol. 9, pp. $37-43$.

Schneider, I. E., (2000), Response to conflict among wilderness visitors, In McCool, S. F., Cole, D. N., Borrie, W. T., \& O'Loughlin, J., Wilderness science in a time of change conference, USDA Rocky Mountain Research Station, Fort Collins.

Schneider, I. E., \& Hammitt, W. E., (1995), "Visitor response to outdoor recreation conflict: A conceptual approach", Leisure Sciences, vol. 17, no. 3, pp. 223-234.

Schuster, R., Hammitt, W. E., \& Moore, D., (2003), "A theoretical model to measure the appraisal and coping response to hassles in outdoor recreation settings", Leisure Sciences, vol. 25, no. 2-3, pp. 277-299.

Schuster, R., Hammitt, W. E., \& Moore, D., (2006), "Stress appraisal and coping response to hassles experienced in outdoor recreation settings", Leisure Sciences, vol. 28, no. 2, pp. 97-113.

Sutherland, W. J., (1996), From individual behaviour to population ecology, Oxford University Press, Oxford.

Sun, W., Cui, H., \& Xu. C., (2018), "Innovative mode of integrated development of higher vocational education based on social interaction theory", Educational Sciences: Theory \& Practice, vol. 18, no. 6, pp. 3043-3051.

Taylor, S. E., \& Schneider, S. K., (1989), "Coping and the simulation of events", Social Cognition, vol. 7, no. 2, pp. 174-194.

Tynon, J. F., \& Gómez, E., (2012), "Interpersonal and social values conflict among coastal recreation activity groups in Hawaii”, Journal of Leisure Research, vol. 44, no. 4, pp.531-543.

Thapa, B., \& Graefe, A. R., (1999), Gender and age group differences in recreational conflict and tolerance among adult skiers and snowboarders, In Vogelsang, H. G., Proceedings of the 1998 Northeastern Recreation Research Symposium, Gen. Tech. Rep. NE-241.

Thyne, M., \& Lawson, R., (2001), "Research note: Addressing tourism public policy issues through attitude segmentation of host communities", Current Issues in Tourism, vol. 4, no. 2-4, pp. 392-400.

Tynon, J. F., \& Gómez, E., (2012), "Interpersonal and social values conflict among coastal recreation activity groups in Hawaii", Journal of Leisure Research, vol. 44, no. 4, pp. 531-543. 
Usher, L. E., \& Gomez, E., (2019), "Managing stoke: Crowding, conflicts and coping among Virginia Beach surfers", Journal of Park and Recreation Administration, vol. 35, no. 2, pp. 9-24.

Urry, J., (1990), The tourist gaze: Leisure and travel in contemporary societies, Sage Publications, London.

Vaske, J. J., \& Donnelly, M. P., (2002), "Generalizing the encounter--norm--crowding relationship", Leisure Sciences, vol. 24, no. 3-4, pp. 255-269.

Vaske, J. J., Donnelly, M. P., Wittmann, K., \& Laidlaw, S., (1995), "Interpersonal versus social - values conflict", Leisure Sciences, vol. 17, no. 3, pp. 205-222.

Wright, S. C., Aron, A., McLaughlinVolpe, T., \& Ropp, S. A., (1997), "The extended contact effect: Knowledge of cross-group relationships and prejudice", Journal of Personality and Social Psychology, vol. 73, no. 1, pp. 73-90.

Yagi, C., (2001), "How tourists see other tourists: Analysis of online travelogues", Journal of Tourism Studies, vol. 12, no. 2, pp. 22 - 31.

Yagi, C., \& Pearce, P. L., (2007), "The influence of appearance and the number of people viewed on tourists' preferences for seeing other tourists", Journal of Sustainable Tourism, vol. 15, no. 1, pp. 28-43.

Yoo, J., \& Sohn, D., (2003), "The structure and meanings of intercultural interactions of international tourists", Journal of Travel and Tourism Marketing, vol. 14, no. 1, pp. 5568.

Yrizarry, N., Matsumoto, D., \& Wilson-Cohn, C., (1998), "American-Japanese differences in multiscalar intensity ratings of universal facial expressions of emotion", Motivation and Emotion, vol. 22, no. 4, pp. 315-327.

Yu, J., \& Lee, T. J., (2014), "Impact of tourist' intercultural interactions", Journal of Travel Research, vol. 53, no. 2, pp. 225-238. 